\title{
USING STORYTELLING TO UNDERSTAND A COMPANY'S LEAN JOURNEY
}

\author{
Carlos Alexandre M. do A. Mourão ${ }^{1}$, Antonio N. de Miranda Filho², Rebeca Nara \\ Nogueira $^{3}$, José de P. Barros Neto ${ }^{4}$, and Jorge Moreira da Costa ${ }^{5}$
}

\begin{abstract}
Lean implementation has become a recurring topic in literature. Scholars have studied lean tools, implementation barriers and proposed strategies, audit tools, and maturity models to overcome such barriers. However, despite the importance of these methods, over the years, researchers have realized that "best practices" emerge from a combination of contextual factors and coherent strategic choices affecting workforce management, supplier relationship, and other "soft" factors. Therefore, through exploratory research structured according to business storytelling fundamentals, the authors describe a company's lean journey along a timeline to provide an overview to understand the strategic choices and even the underlying rationale aligning strategic, tactical, and operational level decision-making. Findings suggest that lean implementation is a neverending journey, which requires organization-wide changes for achieving success. Furthermore, strategic choices enhancing organizational stability and predictability seem to have played a crucial role in the company's success in lean implementation, knowledge retention, and capability development.
\end{abstract}

\section{KEYWORDS}

Lean implementation, organizational stability, strategic choices, business storytelling.

\section{INTRODUCTION}

Nearly twenty years have passed since the day a construction manager heard from an employee a comment that would start a paradigm shift within his company. While talking to a group of workers about the importance of getting everybody involved in construction planning, one foreman stepped up and said: "Thinking ahead is asking too much from individuals that spent most of their young lives in poverty and grew up not knowing what they would have for breakfast the next morning. Getting them to contribute beyond their job description is a hard task when they are not even sure if they will still be employed when the project is over". That construction manager now recalls that that was when it became clear that short-term thinking was a major constraint to workforce commitment

1 PhD Candidate, Civ. Eng. M.Sc., Fac. of Engin., Univ. of Porto, Technical Director, C. Rolim Engenharia, Fortaleza/Bazil, alexandre@crolim.com.br, orcid.org/0000-0001-9711-970X

2 Civil Engineer, Ph.D., CEO, Construtora Santo Amaro Ltda., Fortaleza, Ceará, Brazil, anmirandaf@yahoo.com.br, orcid.org/0000-0001-8107-5159

$3 \quad$ M.Sc. Candidate, Fed. Univ. of Ceará, rebecanara@alu.ufc.br, orcid.org/0000-0002-4423-500X

4 Professor, Dept. of Acad. and Technol. Integ., Fed. Univ. of Ceará, Fortaleza/Brazil, jpbarros@ ufc.br, orcid.org/0000-0001-5131-4593

5 Assoc. Professor, Faculty of Engineering, University of Porto, Portugal, jmfcosta@fe.up.pt, orcid.org/0000-0002-7128-2952 
and effective lookahead planning. It made people in the company realize that lack of predictability and stability were problems that needed to be tackled to reduce short-term thinking amongst employees and subcontractors.

Time passed, that manager progressed to become a Senior Director while the company embarked on a journey to become a lean construction practitioner. This paper tells the company's story depicting relevant events and lean implementation stages along a timeline through a qualitative research approach. This case study can provide a deeper understanding of implementation details and decision patterns to answer the following research questions: What strategic choices fostered its successful lean journey? What was the common rationale behind structural and infrastructural decisions made during the journey? The main objective is to show an overview of implementation steps and strategic choices along the timeline. Although findings from a single case study should not be generalized, the story presented seeks to bring awareness to strategic choices to create organizational stability and predictability for broader lean implementation.

\section{LEAN IMPLEMENTATION IN CONSTRUCTION PROJECTS}

Although lean implementation is a recurring topic in literature, research efforts are often focused on isolated tools. This focus is mainly because of barriers to a more comprehensive adoption of lean principles and practices. Throughout the years, studies were conducted to assess factors affecting lean implementation like lack of theoretical understanding, poor top management support, absence of knowledge sharing, and inappropriate culture, to mention a few (Buch and Sander 2005; Torp et al. 2018). To overcome such barriers, academics and consultants have proposed implementation strategies, audit tools, and maturity models (Serpell et al. 1996; Comelli et al. 2019). But despite the importance of these methods, they are sometimes too prescriptive and based on scholar's interpretations of what is needed.

Another problem is that lean construction has been mostly approached from a project management perspective and not as often from an organizational one. Researchers put much effort into finding the perfect resource and task match to accomplish project schedules. Consequently, the development of project production systems has been focused on structural decisions, such as resource capacity, facilities, equipment, and technology. Nevertheless, in the last years, there has been an increasing realization that true "best practices" mainly emerge from the combination of contextual factors and infrastructural decisions affecting organizational culture, quality control, workforce management, and other "soft" factors. These aspects are less noticeable and frequently overlooked because they involve top management decision-making and cause impacts that extend beyond project boundaries. Acknowledging infrastructural decisions within production strategy helps understand the multiple, equally effective ways organizations can achieve environmental and internal fit to compete within a particular industry (Christiansen et al. 2003). It also helps understand the importance of an organizational approach to the coherent adjustments needed at various levels on a lean journey.

\section{METHODOLOGY}

This paper presents well-documented exploratory research to draw lessons from a construction company's experience. A qualitative approach involving open-ended interviews was used to provide an in-depth account of events, contextual conditions, and challenges. Initially, a timeline was formed with five people who were interviewed, 
including former employees who directly worked with lean implementation. Internal reports, publications, and other sources were also consulted to recall specific details and dates. Nevertheless, one of the authors has worked in the company for more than two decades, playing an active role in much of the implementation effort.

This paper is structured according to storytelling fundamentals to allow a narrative account of events. The storytelling method's suitability for exploratory research comes from the fact that stories are narrative since they understand events and construct their reality. By binding facts and ideas coherently, stories follow a succinct organization to convey the core message and help readers absorb it. Consequently, business storytelling is a process involving chronology and causality that needs to have a clear goal or core message established before moving forward (Denning 2005). Stories also need a situational context, describing the particular time and place (Escalas 2004). Fog et al. (2005) add that there are four elements in storytelling: the message (or goal), the conflict (or problem), the characters (or persons), and the plot (or timeline).

\section{THE JOURNEY TOWARDS LEAN}

Founded in 1977, this case study company worked for many years as a contractor for private investors before becoming a developer and builder of luxury high-rise residential and commercial building projects in Fortaleza, Brazil. Product flexibility, quality, and delivery are the three important performance criteria in the firm's market segment, while internally continuous improvement has always been another criterion. This can be observed in the words of its CEO and founder: "We want to be the locomotive moving the construction industry and setting the pace of innovations. Not just another wagon being pulled by inevitable changes". The company's strive for excellence in a neverending lean journey is described in the timeline below.

\section{8}

This year can be considered a landmark in the company's journey towards higher stability and predictability. The company was then a well-respected general contractor known for delivering projects on time and budget. However, engaging in different projects in various places hindered the company from obtaining more competitive prices and schedules. This problem was partially due to difficulty in establishing long-term cooperation with subcontractors and suppliers. Uncertainty in customer demand made forecasting difficult and pressured its financial return. To reduce such variation sources, the company made the strategic level choice to gradually focus more on developing its residential projects in the town of Fortaleza. On the operational project level, the company began implementing the ISO9001, aiming to certify that it was applying consistent business processes and establishing procedures that would enhance the stability of all critical processes.

\section{4}

By this time, the foreman's words echoed across the organization. Moreover, it became clear that the Quality Management System alone would not fulfill the expectations of enhanced process stability and performance. This was because ISO9001 was originally conceived to help relatively steady organizational systems control and continuously improve performance. So, the company searched for new ideas to further reduce variation sources. Consequently, the company sent employees to a local conference called CONENX, where the focus was on lean construction theory and practice. There, the company staff not only had their first contact with the topic of lean thinking but also met 
members of the INOVACON Building Technology Program, which aims at transferring the state of the art technology from various fields of the AEC industry to the participating firms, including innovative production principles and practices. The INOVACON members were in distinct stages of implementing the same bundles of lean practices and were openly sharing their knowledge. That year, the company joined the Program hoping, as discussed by Christiansen et al. (2003), that a strategic group membership would give the company a better understanding of which bundles of practices to implement. This strategic decision was quite handy due to resource constraints. The $5 \mathrm{~S}$ approach was the company's first experiment with lean tools and was used for planning the construction site in terms of defining fixed storage areas and pathways for materials and personnel.

\section{5}

The company proceeded with its journey by setting up a library consisting of proceedings from previous IGLC conferences and books on project management. The objective was to motivate and facilitate the study of lean thinking in the company. Simultaneously, two top managers began to pursue a Master's Degree with its support. At the operational level, the company continued testing other lean tools in its ever-increasing effort to pursue stability and predictability. The Last Planner System (LPS) provided a disciplined approach to short-interval planning, allowing influence over factors upstream and reducing workflow variations. In addition, a Heijunka box with Kanban cards and mortar batch identification gadgets was installed near the mortar mixing machine. It was possible to enhance lateral relations between work teams and reduce inflow variations in terms of production orders and material delivery to work stations. Moreover, different Andon systems were devised to improve communications between specialists and management teams, using visual aids and color codes to show ongoing operations on different floors and prevent possible workplace disturbances. Lean also raised awareness on waste generation. Therefore, the company started to implement cleaner production and end-ofpipe technologies that mitigate production's environmental burden.

\section{6}

The company maintained its commitment to employee development by supporting those pursuing a Master's qualification. It also paid for them to attend conferences in their field. That same year, the company presented for the first time one paper at the IGLC (Kemmer et al. 2006), demonstrating developments made in terms of Andon systems and construction planning methods. The company also hired a Master's Degree holder to work as a Lean Coordinator to coordinate developments and further implement lean thinking. As a result, the company moved on to implement Poka-Yoke devices in construction processes. The company also began to use procurement strategies promoting relational contracting with subcontractors to create what can be described as project partnering. These partnerships were seen as the starting point to creating proximity between firms in terms of work methods, standards, language, business mores, and policies, which among other things, would ultimately enhance overall predictability and stability.

\section{7}

The company had then wholly shifted from being a contractor to becoming a full-time builder and developer and made the strategic choice to focus on building high-rise skyscrapers in the city of Fortaleza. By focusing on a specific customer segment and particular geographic area, the company aimed to reduce exposure to unknown factors, thereby further improving stability. Underlying this strategic orientation was the notion 
that a system cannot achieve management goals nor be improved if it is not stable. This year also marked the beginning of the company's A3 usage history, which employees from different hierarchical levels used for problem-solving, knowledge recording, and strategic planning. The company continued to support employees in postgraduate courses and pay for them to attend or speak at conferences. The knowledge acquired from internal developments was also shared through a paper published in IGLC (Kemmer et al. 2007).

\section{8}

Even though the company's lean journey had full support from top management, things did not always go as planned, and there was resistance to change. By this point, managers and workers left the company after disagreeing with implementation efforts. To establish a lean mindset amongst employees, the company continued to offer lectures on Hansei and Kaizen to build consciousness on the need to acknowledge problems and improve continuously. The company started to make Hansei and Kaizen events for each construction site, in which the employees share knowledge and identify opportunities to improve the processes. These events happen at the end of each milestone for construction, and a final Hansei event happens to summarize all the lessons learned. That year, two top managers obtained their Master's Degrees, while others received financial assistance to undertake undergraduate and postgraduate courses. Staff members continued to attend or speak at conferences. Furthermore, the company published papers in conferences (Kemmer et al. 2008) and a book about solid waste management was released.

\section{9}

Employee welfare became a big concern, and the company started offering dental and health insurance plans apart from their regular salary and profit-sharing to enhance the employee's well-being and connection to the organization. The company continued to support employee development by offering training sessions. Managers were also encouraged to attend industry, and academic events, such as the Greenbuilding Int'l. Conf. \& Expo of USGBC in Phoenix, USA. A paper reporting lean thinking in the company's head office was published (Kemmer et al. 2009). A practical guide to environmental management and waste management written by staff members was also published. That year, research was conducted to develop a supply method based on the milk run and justin-time principles. The company also started an Environmental Sustainability Program, hoping to become more socially responsible while maintaining economic vitality. The company launched its "Green Commitment" program, in which for each square meter of land purchased, the company plants and takes care of a tree in a public space in Fortaleza.

\section{0}

A Research and Development (R\&D) team was formed to work alongside the Lean Coordinator on rethinking and improving existing business processes. Their first task was to study a way of putting lean philosophy into the Quality Management System, thereby creating a "Lean Quality System." Another study aimed to apply lean practices for customization while maintaining flow and low inventory levels. Staff members continued to exchange knowledge and experience by presenting papers (Kemmer et al. 2010). Meanwhile, Laboral Gymnastics was included to reduce stress and physical discomforts caused by postural problems and repetitive strain and improve employee welfare. 


\section{1}

The next challenge was knowing how much lean thinking was embedded in the organization. Thus, internal audit checklists were revised to make people in the company think about customer satisfaction and work more effectively and efficiently. The main objective was to reinforce a culture of continuous improvement. In parallel, the company continued to build a stable workforce by offering a private pension plan to employees.

\section{2}

Benchmarking started being used to compare the company's success in terms of lean implementation against direct competitors and companies in other industries. Internal benchmarking was also adopted within the company's construction sites to identify best practices and improvement opportunities. As a result, an internal study group was formed to write a Lean Guidebook to retain organizational knowledge and provide instructions for future construction projects. Other study groups aimed to learn and share insights on trending topics such as BIM and Lean \& Green. Company managers continued to regularly attend or speak at relevant conferences. They also presented a paper on lean monitoring and evaluation at the IGLC (Valente et al. 2012).

\section{3}

The company was already a well-established lean practitioner and getting significant international attention. Lean practitioners and academics worldwide had the remarkable opportunity to see up close its improvements during the IGLC held in Fortaleza, where the company performs its activities. The visit to one of the company's construction sites during Industry Day was a highly attended event. R\&D team members authored four papers (Costa et al. 2013; Valente et al. 2013; Valente et al. 2013a; Rocha and Kemmer 2013) detailing improvements. In the following months, one of the study groups worked on revising and updating the Lean Guidebook. A second group assembled a collection of papers on Lean \& Green written by the company's R\&D team. A third group offered introductory training sessions on BIM.

\section{4}

The continuous effort to increase stability and plan reliability led to establishing work standards in terms of objectives, methods employed, team size, work pace, and work paths. First Run Studies began to be used early on to identify constraints and incorporate improvements, leading to a better adjustment between product and work content. Pursuing standardized work also led to acquiring technology for Virtual Gemba Walks to gather continuous improvement ideas. Openness to sharing these and other results led staff members to publish another paper (Valente et al. 2014) and attend conferences. Furthermore, the company's growing commitment to sustainability began to pay off with Brazil's first LEED-certified residential project.

\section{5}

The search for sustainable methods was viewed as another step of the lean journey; hence the company made an effort towards sustainable practices by controlling some environmental metrics and searching for innovative and technological constructions methods to reduce these environmental metrics by diminishing waste production, water usage, and greenhouse gases emissions. The $R \& D$ team prepared a management report with guidelines based on sustainability reporting standards proposed by the GRI (Global 
Reporting Initiative). The company soon started working on reducing carbon emissions and undertaking carbon offset projects to complement internal initiatives. Staff members attended the Greenbuilding Brasil Conferência Internacional \& Expo, and sustainability was the topic of one the papers published that year (Saggin et al. 2015).

\section{6}

The company took another step towards higher stability and predictability, adopting the BIM capabilities related to time (4D BIM) and cost management (5D BIM). The objective of adding these dimensions was to enable better-planned and more cost-effective construction and better manage the effects of change orders by identifying possible reworks before making any changes. The company also started a Total Productive Maintenance (TPM) Program focused on proactive and preventive techniques for improving equipment safety and reliability. Cranes, racks, and pinion elevators used to transport working materials and people were the major concerns. During that time, the company's R\&D team published papers (Fernandes et al. 2016) and spoke at IGLC, CONENX, and Lean Summit conferences.

\section{7}

The company created a Lean Committee composed of managers from different functional areas to make decisions concerning lean progress as a group and ensure that all views are looked at. Concern regarding sustainability practices was also pushed forward. A study group was formed to perform a Life Cycle Assessment (LCA) on the cumulative impacts and emissions to the environment derived from energy and materials required across the company's value chain. As an initial result of the LCA study, the company launched its plan to plant forty thousand trees in a local state park. Staff members also attended the BATIMAT and the IGLC, where they published another paper (Saggin et al. 2017).

\section{8}

After a few years of waiting, the company finally received an invitation to visit Toyota's manufacturing facility in Brazil. To get the most out of the day, staff members took the guided tour with the clear objective of observing lean processes at work and learning firsthand how they get things done. No other Brazilian construction company had ever done this before. Searching for new insights and technologies, one of the company's top managers participated with other members of the INOVACON in a commercial and academic mission to Silicon Valley. Company managers continued to attend conferences, where they did a paper presentation on workforce well-being (Dantas Filho et al. 2018). Meanwhile, the LCA study advanced, and a company's residential projects received from the local government the first ever-granted Green Factor Certification.

\section{9}

Inspired by observations made during the visit to Toyota's manufacturing facility, the company's R\&D team started to study the fundamentals of Karakuri Kaizen. They began to look for moving objects automatically using gravity, counterweights, and the force of equipment already used in construction sites. The R\&D team also prepared a second edition of the management report based on sustainability reporting standards proposed by the GRI. Company managers traveled to Germany to attend Bauma 2019, the world's largest construction machinery trade fair. Moreover, one of the company's top managers, alongside members of the INOVACON, participated in an academic mission to Columbia University, USA. 


\section{0}

The COVID-19 pandemic impacted the company's performance and plans. Maintaining employee welfare and developing a workplace safety plan to help workers stay healthy and safe at work became the most crucial thing. Moreover, even though coronavirusrelated restrictions imposed social distancing, staff members continued to seek knowledge and exchange experience by publishing one paper (Valente et al. 2020) and attending the virtual CONENX conference.

\section{DISCUSSION}

The company's efforts to acquire and maintain knowledge are noticeable. Employees got support to get their post-graduate degrees and attended conferences such as Lean Summit, CONENX, ENTAC, ENEGEP, and IGLC. The publication of papers by employees to share and consolidate knowledge and experience was encouraged, and the R\&D team detailed the company's experience on the various papers published over the years. As a result, the company was recognized four times as the Best Builder and Developer in Ceará, alongside other awards such as the New Millenium Award (Paris), Social Responsibility Award (Brazil), and the Int'l. Diamond Prize for Excellence in Quality (European Society of Quality Research). Furthermore, representatives of the company were continuously invited to speak at conferences and events, such as Industry Day (Salford University, UK) and the Conference of the Parties (COP 23), which demonstrates its international recognition as a consolidated lean practitioner.

\section{CONCLUSIONS}

Every business has a story to tell and lessons to share. This paper used a story structure to give visibility to two messages. The first message is to understand better underlying strategic choices and how they impact lean implementation. The second message is to capture the rationale behind decision-making and strategic alignment. This comes from the fact that the most successful organizations have a good environmental fit and internal coherence between business strategy, functional strategies, and operational practices. The notion that true "best" practices emerge from several organizational adjustments points to the importance of carefully aligning strategic choices in production strategy, be they structural or infrastructural, with one another and with those in other functional areas like marketing, finance, and human resources.

Under this notion, the company in this case study used an organization-wide perspective while pursuing a new production model. It initially changed the business strategy to gradually develop and build its projects in a specific geographic area, reducing uncertainties regarding consumer behavior, product development, local regulations, and other possible unwanted variation sources. Changing the strategic orientation allowed the company to devise partnering strategies with local subcontractors and suppliers to improve collectively and create more behavioral predictability in the value chain. Moreover, it permitted important infrastructural decisions regarding employee welfare to maintain a skilled and stable workforce. As a result, the company built other explicit strategies for preserving institutional memory and making accessible the knowledge and capabilities developed. Creating organizational commonality in language, culture, and work standards was another way of preventing disturbances. These and other strategic choices indicate that the search for predictability and stability was the underlying rationale for creating coherent decision-making throughout its lean journey. 
The story presented indicates that stabilizing the work environment requires more than implementing the Last Planner System and other operational level practices from the lean toolbox. In a dynamic environment like the construction sector, understanding the implications of individual or combined strategies can be crucial to shielding production from upstream variation and enhancing project performance. As shown in this business case, the strive for excellence starts with the formalization of strategic choices in production strategy. Although commonly overlooked by lean construction literature, if carefully chosen and made explicit, the strategies applied alongside lean practices can help create a project production system where methods and outputs are less uncertain.

\section{ACKNOWLEDGMENTS}

The authors would like to thank CRolim Engenharia's management team for sharing their valuable experience and Pio Rodrigues Neto, especially, for showcasing the true spirit of lean thinking. The authors would also like to thank the INOVACON Building Technology Program and the GERCON team for providing support throughout the company's lean journey. The authors are also grateful to Ricardo Miranda M. de Sousa for his teachings.

\section{REFERENCES}

Buch, S. and Sander, D. (2005). "From Hierarchy to Team - Barriers and Requirements in Relation to a New Organization of Building Sites." Proc. 13th Ann. Conf. Int'l. Group for Lean Construction, Sidney, Australia.

Christiansen, T., Berry, W.L., Bruun, P., and Ward, P. (2003). "A Mapping of Competitive Priorities, Manufacturing Practices, and Operational Performance in Groups of Danish Manufacturing Companies." Int'l. Journal of Operations \& Production Management 23 (10), 1163-1183.

Comelli, M. L., Carvalho, Y. M. V., Marinho, R. C., Candido, L. F., Barros Neto, J. P. (2019). "Assessing the Level of Implementation of Lean Construction: an Audit Protocol." Proc. 27th Ann. Conf. Int'l. Group for Lean Construction. Dublin, Ireland.

Costa, H.M., Silva, M.V.V., Mourão, A., Valente, C.P, and Laércio, F. (2013). "Redesigning Administrative Procedures Using Value Stream Mapping a Case Study" Proc. 21th Ann. Conf. Int'1. Group for Lean Construction. Fortaleza, Brazil.

Dantas Filho, J.B.P., Barros Neto, J.P., Mourão, A., Rocha, A.B., Luccas, A.V., and Saggin, A. (2018). "Respect for People's Well-Being: Meditation for Construction Workers.” Proc. 26th Ann. Conf. Int'l. Group for Lean Construction. Chennai, India.

Escalas, J. E., (2004). "Imagine Yourself in the Product: Mental Simulation, Narrative Transportation and Persuasion. Journal of Advertising, Summer 2004.

Denning, S. (2005). "The Leader's Guide to Storytelling. Mastering the Art and Discipline of Business Narrative." Jossey-Bass. A Wiley Imprint. San Francisco.

Fernandes, N.B.L.S., Valente, C.P., Saggin, A.B, Brito, F.L., Mourão, C.A.M.A., and Elias, S.J.B. (2016). "Proposal for the Structure of a Standardization Manual for Lean Tools and Processes in a Construction Site." Proc. 24th Ann. Conf. Int'1. Group for Lean Construction.

Fog, K., Budtz. C., Yakaboylu, B. (2005). "Storytelling - Branding in Practice". SpringerVerlag, Berlin, Heidelberg.

Kemmer, S.L. , Saraiva, M.A. , Heineck, L.F.M. , Pacheco, A.V.L. , Novaes, M.V. , Mourão, C.A.M.A. \& Moreira, L.C.R. (2006), 'The Use of Andon in High Rise Building" Proc. 14th Ann. Conf. Int'l. Group for Lean Construction Santiago, Chile. 
Kemmer, S.L., Heineck, L. F.M., Novaes, M.V., Mourao, C.A.M.A., and Alves, T.C.L. (2007). "Medium-Term Planning: Constributions Based on Field Application." Proc. $15^{\text {th }}$ Ann. Conf. Int'l. Group for Lean Construction, Michigan, USA.

Kemmer, S.L., Heineck, L.F.M., and Alves, T.C.L. (2008). "Using the Line of Balance for Production System Design.” Proc. 16th Ann. Conf. Int'1. Group for Lean Construction, Manchester, UK.

Kemmer, S. L., Alves, T. C., Macedo, M., Novaes, M. V., and Neto, J. P. B. (2009). "Lean Office at a Construction Company." Proc. 17th Ann. Conf. Int'l. Group for Lean Construction, Taipei, Taiwan.

Kemmer, S. L., Rocha, C. G., Meneses, L., Pacheco, A. V. L., Formoso, C. T. (2010). "Application of Lean Principles to Manage a Customisation Process". Proc. 18th Ann. Conf. Int'l. Group for Lean Construction.

Mohan, S.B. and Iyer, S. (2005). "Effectiveness of Lean Principles in Construction." The 13th Ann. Conf. Int'l. Group for Lean Construction, Sidney.

Rocha, C. G. da, and Kemmer, S. L. (2013). "Managing the Information Flow in Customised Apartment Building Projects." Proc. 21th Ann. Conf. Int'1. Group for Lean Construction, Fortaleza, Brazil.

Saggin, A. B., Valente, C. P., Mourão, C. A. M. A., and Cabral, A. E. B. (2015). "Comparing Investments in Sustainability With Cost Reduction From Waste Due to Lean Construction.” Proc. 23rd Ann. Conf. Int'l. Group for Lean Construction.

Saggin, A. B. , Mota, T. R. , Brito, F. L. \& Mourão, C. A. M. A. (2017). "Standardized Work: Practical Examples in a Brazilian Construction Company." Proc. 25th Annual Conference of the International Group for Lean Construction. Heraklion, Greece.

Serpell, A., Alarcón, L. F., Ghio, V. (1996). "General Framework for Improvement of the Construction Process". Proc. $4^{\text {th }}$ Ann. Conf. Int'l. Group for Lean Construction, Birmingham, UK.

Torp, O., Knudsen, J. B., Ronneberg, I. (2018). "Factors Affecting Implementation of Lean Construction." Proc. 26th Ann. Conf. Int'l. Group for Lean Construction, Chennai, India.

Valente, C.P., Novaes, M.D.V., Mourão, C.A.M.D.A., Barros Neto, J.D.P. (2012). "Lean Monitoring and Evaluation in a Construction Site: A Proposal of Lean Audits." Proc. 20th Ann. Conf. Int'1. Group for Lean Construction. San Diego, USA.

Valente, C. P., Montenegro, G. A., Brito, F. L., Biotto, C. N., Mota, B. P., and Schramm, F. K. (2013). "Benefits of Batch Size Reduction: A Case Study in a Residential Project." Proc. 21th Ann. Conf. Int'l. Group for Lean Construction. Fortaleza, Brazil.

Valente, C.P., Mourão, C.A.M.A., and Barros Neto, J.D.P. (2013). "Lean and Green How Both Philosophies Can Interact on Strategic, Tactical and Operational Levels of a Company." The 21th Ann. Conf. Int'1. Group for Lean Construction. Fortaleza, Brazil.

Valente, C.P., Montenegro, G.A., Brito, F.L., Biotto, C.N., and Mota, B.P. (2014). "Guidelines for Developing a Line of Balance for Non-Repetitive Areas (Common Areas) at a Vertical Residental Building." Proc. 22nd Ann. Conf. Int'l. Group for Lean Construction.

Valente, C.P., Mourão, C.A.M.A., Saggin, A.B., Barros Neto, J.P., and Costa, J.M. (2020). "Achieving Excellence in Lean Implementation at Construction Companies - A Case Study From Brazil." Proc. 28th Ann. Conf. Int'1. Group for Lean Construction, Berkeley, California, USA. 